\title{
Avanços e contradições da Política de Educação Profissional integrada no Paraná (2003-2010)
}

\author{
Advances and contradictions of the integrated Professional \\ Education Policy in Paraná (2003-2010)
}

\section{Letícia de Luca Wollmann Saldanha1 Rita de Cássia da Silva Oliveira ${ }^{2}$}

\section{Resumo}

O artigo apresenta uma análise na perspectiva histórico-dialética do processo de constituição da Política de Educação Profissional no Paraná - concepção e ações compreendidos entre os anos de 2003 a 2010 -, situados nos projetos da sociedade e da educação dos séculos XX e XXI. Utilizaram-se como referenciais teóricos os conceitos de Estado ampliado e intelectual de Gramsci (1987; 1991) e o de ideologia de Löwy (2007). A metodologia de investigação consistiu em pesquisa bibliográfica; análise de documento e legislação. Este período representa um avanço, ao incorporar os princípios da politecnia e formação humana, defendidos por grupos da sociedade civil dos anos 1980. Através de uma ideologia crítica ao capitalismo e à concepção liberal conservadora dos anos 1990 e pela ação de seus intelectuais, sintetiza um processo de humanização e de qualificação para o trabalho, limitado pela política de financiamento.

Palavras-chave: Política Educacional. Educação Profissional. Educação Profissional Integrada no Paraná.

\begin{abstract}
This article presents an analysis under the historic-dialect perspective of the development of the Professional Education Policy in Paraná (both regarding its conception and actions) from 2003 to 2010 as well as their meaning to social and educational projects dated from the $20^{\text {th }}$ century and currently under debate. Gramsci's concepts of extended State and intellectual (1987; 2001) and Löwy's concept of ideology (2007) were used as theoretical bases. The research methodology consisted of a bibliographical research; an analysis of the document and law. Its conception represent an advance retrieves the primary concept of polytechnic education and understanding of human education supported by part of the civil society in the 1980s. That reveals an ideology characterized by criticism towards capitalism and the conservative liberalism of the 1990s, represented by actions carried out by intellectuals, synthesises the humanization and work training process, limited by the financing policy.
\end{abstract}

Keywords: Educational Policy. Professional Education. Integrated Professional Education in Paraná.

1 Graduada em Direito pela UFPR e Esquema I pelo CEFET- Pr. Mestre em Educação pela UEPG. Professora da Educação Profissional da Rede Estadual de Educação do Paraná. leticialws@hotmail.com

2 Pós Doutora pela Universidade de Santiago de Compostela. Professora do Mestrado e Doutorado em Educação na Universidade Estadual de Ponta Grossa. E-mail: soliveira13@uol.com.br 


\section{Introdução}

Para compreender a recente Política de Educação Profissional do Paraná (2003-2010) da rede estadual, procurou-se estabelecer como concepção, um eixo dialético, capaz de nortear a política e as ações realizadas nas relações com as determinações sócio-econômicas e político-ideológicas, culturais e histórico-legais mais amplas, presentes no campo estrutural e conjuntural. As décadas de 1980 e de 1990 apresentam uma conjuntura histórica importante para a pesquisa, assim como o campo estrutural. Considera-se que o

[...] campo estrutural fornece a materialidade dos processos históricos de longo prazo e o campo conjuntural indica, no médio e no curto prazo, as maneiras como os grupos, classes ou frações de classes, em síntese, as forças sociais que disputam seus interesses e estabelecem relações mediadas por instituições, movimentos e lutas concretas (FRIGOTTO, 2006, p. 27).

O Decreto n 5154/04 que delimita legalmente a Política com base na Lei de Diretrizes e Bases da Educação Nacional (LDB), restabeleceu a oferta da Educação Profissional na forma integrada ao Ensino Médio e conservou as formas concomitante e subsequente (art. $4^{\circ} \& 1^{\circ}$ ). Representa um avanço em relação aos efeitos ocasionados pelo Decreto n 2208/97 - como o de restrição da Educação Profissional pública no estado do Paraná -, embora não tenha rompido com o dualismo histórico.

No Brasil, "[...] o dualismo se enraíza em toda a sociedade através de séculos de escravismo e discriminação do trabalho manual" (FRIGOTTO; CIAVATTA; RAMOS, 2005, p. 32) articulado à nossa formação econômicosocial - de cultura escravocrata e colonizadora associada ao grande capital -, e pela construção reiterada de um projeto de classe dominante e de seus intelectuais para a sociedade brasileira (FRIGOTTO, 2006).

A formação social brasileira sintetiza a desigualdade e a discriminação, presentes na formação dos jovens brasileiros sobredeterminados pela dualidade histórica, gerada pela sociedade de classes. Daí a importância da análise de Políticas Educacionais que pretendem, ainda que nos limites do capitalismo, romper com as tendências neoliberais que, ideologicamente, se impuseram no século passado e que se apresentam na educação no século atual, como consequência da opção dominante brasileira de capitalismo dependente ${ }^{3}$, com desenvolvimento desigual e combinado (FERNANDES, 1975, 1985; OLIVEIRA, 1972; CARDOSO, 2005; FRIGOTTO, 2009).

Zibas (2005) reflete que, além das nossas raízes histórico-sociais, um dos veios da herança de desvalorização do ensino técnico-profissional encontra-se na adesão ao modelo educacional francês, caracterizado segundo Dubet (2003) como resistente ao ensino técnico e profissional relegando esse ensino para carreiras desvalorizadas, como um "confinamento simbólico" (DUBET apud ZIBAS, 2005, p.1069).

Na análise do Decreto $n^{\circ}$ 5154/04, que fez parte do governo de Luiz Inácio Lula da Silva, e que revogou o anterior Decreto n²208/97, vários autores têm se posicionado. Dentre eles, Frigotto, Ciavatta e Ramos (2005), mostram que o expediente do decreto foi utilizado em virtude da urgência e que o embate com as forças conservadoras no Congresso Nacional exigiria um trâmite longo; e, em relação ao seu conteúdo, seria capaz de expressar um ganho político, ao sinalizar mudanças ou consolidar o dualismo, desde que apropriado pelos interesses definidos pelo mercado.

Guimarães (2007) defende que um projeto de escola única e politécnica4 (SAVIANI, 1989, p. 17), para ser

30 conceito de capitalismo dependente de Florestan Fernandes (1985, p. 50) apresenta-se como "[...] a forma periférica e dependente do capitalismo monopolista, o que associa inexorável e inextricavelmente as formas 'nacionais' e 'estrangeiras' do capital financeiro". Esta especificidade do capitalismo, que combina elevada concentração de riqueza e capital e desigualdade, representa a síntese de nossa formação econômico-social e consequentemente, repercute na formação realizada pela Educação Profissional.

4 "A noção de politecnia diz respeito ao domínio dos fundamentos científicos das diferentes técnicas que caracterizam o processo de trabalho moderno. Politecnia, nesse sentido, se baseia em diferentes princípios, determinados fundamentos e a formação politécnica deve garantir o domínio desses princípios, desses fundamentos" (SAVIANI, 1989, p. 17). Esta noção deriva do trabalho como princípio educativo geral e "[...] na direção da superação entre trabalho manual e trabalho intelectual, entre instrução profissional e instrução geral" (id. ibid., p. 13). 0 termo clássico "politecnia" tem a preferência de Saviani (1989) por implicar a união entre escola e trabalho, utilizada por Marx nas Instruções e em 0 Capital. Nosella (2007) em Trabalho e perspectivas de formação dos trabalhadores: para além da formação, faz a crítica ao termo "formaç̧ão politécnica" por entender que expressa uma posição teórica ultrapassada. Este autor defende a tese gramsciana da escola unitária, por conter a categoria antropológica da liberdade histórica de todos os homens. 
hegemônico, necessariamente teria que passar pelo embate com as forças conservadoras, através de um projeto de lei ou na elaboração de novas Diretrizes Curriculares pelo Conselho Nacional de Educação. A autora argumenta que o panorama de flexibilidade da legislação continua, pois as Diretrizes Curriculares para o Ensino Médio e para a Educação Profissional de Nível Técnico foram preservadas, não garantindo o desenvolvimento de um currículo único para todo o Ensino Médio.

Portanto, o Decreto n 5154/04, por ser parte da realidade brasileira e das relações contraditórias entre trabalho, educação e capital expressou a síntese conciliatória das disputas, das "visões sociais de mundo" que, segundo Löwy (2007) representam a ideologia.

Somente em 2007 a Secretaria de Educação Profissional e Tecnológica expôs em documento (BRASIL, MEC/SETEC, 2007) a sua concepção teórica em relação à integração, que se aproxima à concepção da Secretaria de Estado da Educação do Paraná (PARANÁ, 2005). No entanto, o documento realizado no ano seguinte, com a Secretaria de Educação Básica (BRASIL, MEC/SETEC/SEB, 2008) apresentou um novo entendimento para a integração. Os sistemas de ensino realizariam a opção por formações específicas, em relação às seguintes dimensões: a do trabalho, como formação profissional; a da ciência, como iniciação científica e a da cultura como formação cultural. Esta opção dada aos sistemas de ensino apresenta o efeito de fragmentar os eixos da integração.

A Lei $n^{\circ} 11.741 / 08$ (BRASIL, 2008), que altera a LDB após o Decreto $n^{\circ} 5154 / 04$, institucionaliza a Educação Profissional integrada. Atualmente, o Conselho Nacional de Educação (BRASIL, MEC/CNE, 2010) disponibiliza uma Versão Preliminar para debates em Audiência Pública Nacional para a atualização das Diretrizes Curriculares Nacionais para a Educação Profissional, de 1999. Neste documento, a Educação Profissional (mesmo a integrada) tem caráter de complementaridade. A organização curricular é centrada no desenvolvimento de competências profissionais entendidas, "[...] como a capacidade de mobilizar, articular e colocar em ação, Conhecimentos, Habilidades, Atitudes, Valores e Emoções [sigla "CHAVE"] para responder, de forma criativa, aos novos desafios da vida cidadã do trabalho" (BRASIL, MEC/CNE, 2010, p. 20).

A organização da Educação Profissional dá-se segundo a lógica do modelo de desenvolvimento de competências profissionais para a "laboralidade" do trabalhador, significando "a capacidade de transitar por diferentes ocupações no âmbito de um eixo tecnológico" (BRASIL, MEC/CNE, 2010, p. 21) orientada "[...] pelos princípios da flexibilidade, interdisciplinaridade e contextualização" (BRASIL, MEC/CNE, 2010, p. 27).

Portanto, a proposta do Conselho Nacional de Educação reedita mais uma vez, as Diretrizes Curriculares para a Educação Profissional elaboradas em 1999 com base no modelo de competências, acrescentando o novo termo "laboralidade", denominação atual de polivalência. Subordinada ao determinismo tecnológico apresenta uma concepção contraposta à da politecnia, concepção presente na Educação Profissional integrada do Paraná. A reflexão de Arroyo (2007, p. 23) de que "[...] as demandas de competências requeridas pelo capital tiveram, e ainda têm, maior centralidade nos currículos do que os direitos dos trabalhadores aos saberes sobre o trabalho" atualiza-se novamente. De acordo com Frigotto, Ciavatta e Ramos (2005, p. 14), "[...] como sempre, a direção que [a] legislação vai assumir depende das forças em disputa na sociedade e do discernimento do que está em jogo". Daí a importância de se articular ao debate, as forças políticas presentes no âmbito do Estado e as suas defesas, que impactam nos rumos da Educação Profissional.

O artigo apresenta a concepção da Educação Profissional no estado do Paraná segundo o documento "Fundamentos Políticos e Pedagógicos" (PARANÁ, 2005) para a rede pública estadual que se articula às principais ações desenvolvidas, apontando limites e contradições; e, nas considerações finais, procura significar esta Política Educacional em relação aos projetos de sociedade e de educação presentes no século XX que continuam em disputa no século atual. 


\section{A concepção da Política de Educação Profissional integrada no Paraná}

O documento "Fundamentos Políticos e Pedagógicos para a Educação Profissional" (PARANÁ, 2005), elaborado pela Secretaria de Estado da Educação (SEED), compõe-se preliminarmente de um contexto histórico e legal que faz parte do contexto de formulação da Política de Educação Profissional do Paraná.

A concepção apresentada pauta-se na perspectiva de formação humana e que, segundo Ciavatta procura

[...] garantir ao adolescente, ao jovem e ao adulto trabalhador o direito a uma formação completa para a leitura do mundo e para a atuação

como cidadão pertencente a um país, integrado dignamente à sua sociedade política. Formação que, neste sentido, supõe a compreensão das relações sociais subjacentes a todos os fenômenos (CIAVATTA, 2005, p. 8).

A primeira categoria conceitual abordada no documento para a integração é da Educação Básica, entendida como a formação mínima necessária a todo o cidadão que, articulado a Educação Profissional procura romper com a dimensão de subordinação com o mercado de trabalho:

0 assumir dessa concepção traz, em seu arcabouço, o entendimento de que a educação básica de nível médio, tomada como direito social de todo o cidadão, é indissociável da formação profissional requerida para acompanhar as mudanças da base técnica, e assim, aponta para além de uma formação como adaptação às demandas do mercado e do capital e dos padrões da empregabilidade (PARANÁ, 2005, p. 3).

Outra categoria apresentada refere-se ao trabalho como princípio educativo que implica em uma "[...] postura metodológica que permite analisar os projetos educativos a partir das demandas do processo social e produtivo" (PARANÁ, 2005, p. 15) e também do enfrentamento à concepção de trabalho no capitalismo, considerando-se os limites e possibilidades da escola. Configura-se, sobretudo, como um princípio ético-político, pois

[...] considera 0 homem em sua totalidade histórica, e a articulação entre trabalho manual e intelectual a partir do processo produtivo contemporâneo, com todas as contradições daí decorrentes para os processos de formação humana no e para o trabalho (PARANÁ, 2005, p. 11).

A categoria trabalho como princípio educativo conduz à politecnia, adotando-se, "[...] como princípio metodológico, a articulação dialética entre teoria e prática, na perspectiva da práxis” (PARANÁ, 2005, p. 18). A articulação teoria/prática é requerida pelo sistema capitalista visando às necessidades do processo de acumulação flexível (HARVEY, 1992) ${ }^{5}$, que tem como base a microeletrônica (oposta à rigidez do fordismo) e relaciona-se às mudanças no mundo do trabalho e às novas demandas de Educação Profissional, que compõem outra categoria abordada. O processo de acumulação flexível demanda o desenvolvimento de competências ${ }^{6}$ cognitivas complexas: competências comunicativas, desenvolvimento do raciocínio lógicoformal, transdisciplinaridade, capacidade de tomar decisões e de transferir aprendizagens anteriores para situações novas. Um novo trabalhador, com capacidades intelectuais e práticas permite a seguinte positividade pela contradição: "[...] mais do que adaptar-se à produção flexível, compreender os seus limites e organizar-se coletivamente para superá-los" (PARANÁ, 2005, p. 22). Esta colocação encontra analogia na ideia de cultura de Gramsci, no "executar bem" porque "pensar bem" produzindo a personalidade e identidade de classe.

5 Para Harvey (1992) o novo padrão flexível capitalista organiza-se para a retomada dos patamares de acumulação, a partir de uma "produção enxuta" de mercadorias e pelo controle e manipulação do elemento subjetivo do trabalho. A informática, a qualidade, a automação, as redes de mercados, a logística, a terceirização, o marketing, as subcontratações, as franquias, o decréscimo numérico do proletariado e a desindustrialização que aparecem na sociedade configuram um novo estilo de vida.

6 Gotardo e Viriato (2009, p. 231), fazem a crítica ao termo competência: "0 documento Educação Profissional: Fundamentos Políticos e Pedagógicos possui fundamentação teórica amparada em autores situados no campo da crítica ao capitalismo, mas adota o termo competência como parâmetro de formação, indicando ao mesmo tempo distinções e proximidades em relação às Diretrizes Curriculares Nacionais para a Educação Profissional de Nível Técnico". Os autores consideram que a categoria trabalho em sua forma histórica não está desenvolvida claramente, ou seja, na forma concreta que assume no capitalismo, alienada, a qual não deve ser utilizada como princípio educativo (GOTARDO; VIRIATO, 2009). A crítica procede quanto à redação que 0 texto assume, mas não em relação à interpretação do seu conteúdo. É a partir das demandas do processo de acumulação flexível que a formação humana pode realizar-se - por contradição -, e através da Educação Profissional integrada. Esta apresenta uma concepção que diverge da noção de competência que faz parte da legislação nacional vigente e resgata o sentido ontológico da categoria trabalho. 
A seguir, o documento aborda "[...] a incorporação dos princípios de uma escola unitária e de uma educação politécnica ou tecnológica" (PARANÁ, 2005, p. 45). Portanto, faz referência à escola unitária proposta por Gramsci de formação humana, tanto para as atividades intelectuais como para as instrumentais, sob as bases de uma cultura geral formativa de caráter teórico-prático:

[...] a escola unitária, ou de formação humanista... ou de cultura geral deveria se propor a tarefa de inserir os jovens na atividade social, depois de tê-los levado a certo grau de maturidade e capacidade, à criação intelectual e prática e a uma certa autonomia na orientação e na iniciativa (GRAMSCI apud PARANÁ, 2005, p. 16).

A educação politécnica ou tecnológica - outro termo referido no documento - segundo Machado "[...] pressupõe sólida formação básica que contribua para superar a dualidade tradicional entre formação técnica e geral, na perspectiva de uma qualificação ampla, integrada e crítica" (MACHADO, 1994, p. 186) que reforça a finalidade de superação de escolas diferentes para classes sociais distintas.

O termo politecnia está presente em outras partes do documento (PARANÁ, 2005, p. 17-18), referindose também ao desenvolvimento do processo de trabalho que assegure a indissociabilidade entre atividades manuais e intelectuais e adotando o princípio metodológico da articulação dialética entre teoria e prática, na perspectiva da práxis, entendida como "[...] atividade teórica e prática que transforma a natureza e a sociedade; prática na medida em que a teoria, como guia da ação, orienta a atividade humana; teórica, na medida em que esta ação é consciente" (VÁZQUEZ, 1968, p. 117).

Portanto, as perspectivas de formação politécnica e de escola unitária possibilitariam a formação de sujeitos autônomos e responsáveis, reconstruindo suas condições de sujeitos históricos: o acesso à cultura, à ciência e à tecnologia para todos, assegurada, não de forma enciclopedista ou estritamente profissionalizante, mas através do desenvolvimento de capacidades intelectivas e práticas dos alunos, na perspectiva da dimensão formativa da práxis humana.

O processo de construção de um currículo integrado na Educação Profissional do Paraná a partir de uma visão social de mundo crítica e transformadora tenta criar uma identidade profissional diversa da realizada nos cursos profissionalizantes (essencialmente operacional e reprodutora da ordem capitalista). Com base no trabalho de Gouveia (2009), a Política de Educação Profissional do Paraná ao articular-se à transformação, no âmbito de seus pressupostos, associa-se ao eixo de esquerda. Uma das conquistas mais clamorosas dos movimentos socialistas foi o reconhecimento dos direitos sociais, incorporados às legislações ao lado dos direitos de liberdade. A razão de ser dos direitos sociais "[...] é uma razão igualitária" (BOBBIO, 1995, p. 109).

A proposta contida no documento menciona a opção epistemológica de compreensão do processo de conhecimento a partir da atividade humana, incorporando as múltiplas relações do trabalho coletivo. O ato de conhecer, inicialmente teórico, parte do pensamento sobre a realidade e, ao passar à dimensão empírica, estabelece a relação teoria/prática.

A relação parte/totalidade permite ao aluno acesso a formas superiores de compreensão da realidade, pois para se conhecer uma totalidade é necessário relacioná-la à parte (os fatos) mediada pela história. Segundo Kuenzer (PARANÁ, 2005), parte e totalidade, análise e síntese constituem-se em momentos entrelaçados do conhecimento. A dialética, como teoria do movimento da realidade, possui uma lógica concreta, baseada na prática-teoria-prática. A teoria dialética do conhecimento permite a interpretação da realidade contraditória visando a sua superação e possibilita a formação integral do ser humano, segundo a concepção de Educação Profissional abordada.

Outra categoria presente refere-se às relações entre ciência, tecnologia e Educação Profissional. O posicionamento em relação à ciência decorre da discussão de duas abordagens: a primeira, que tem como foco a ciência e tecnologia independentes das relações sociais e a segunda, que tem como foco, a sociedade. Considerando ambas insuficientes, aponta para o redirecionamento dessas relações a favor de interesses mais amplos, a partir dos atores sociais: 
É Gramsci que aponta a saída para este impasse, ao afirmar que a ciência, enquanto produção humana parcial e historicamente determinada, também é uma superestrutura, uma ideologia, mas que ocupa um lugar privilegiado, em decorrência de seus efeitos sobre a infraestrutura (PARANÁ, 2005, p. 30).

Portanto, as ciências sociais vinculam-se à história, são socialmente condicionadas, não possuindo autonomia total. Löwy (2007) situa a relação ideologia/ciência, através da "problemática" que se coloca para a ciência.

O documento menciona a integração entre ciência e tecnologia como determinante da integração entre Educação Básica e Educação Profissional e cita Kuenzer (1988, p. 33): "[...] a simplificação do trabalho contemporâneo é a expressão concreta da complexificação da tecnologia através da operacionalização da ciência" (PARANÁ, 2005).

A visão de ciência e tecnologia ao lado do trabalho e da cultura como eixos curriculares que integram Ensino Médio e Educação Profissional apresenta-se com uma visão social diferente daquela que constituiu a Educação Profissional no período anterior, pois o conhecimento do processo, enquanto conjunto de relações socialmente condicionadas substitui o conhecimento da tarefa supostamente neutra.

Trabalho e ciência deverão formar uma unidade pela mediação da tecnologia criando novas formas de comportamento, ideologias e normas, ou seja, uma nova cultura:

Mesmo que se considere que estas demandas são polarizadas no regime de acumulação flexível e, portanto, não se colocam para todos os trabalhadores, as políticas educacionais que de fato se comprometam com os que vivem do trabalho devem ter a democratização do acesso ao conhecimento como horizonte (PARANÁ, 2005, p. 33).

A concepção da Política de Educação Profissional no Paraná resgata a matriz teórica da politecnia, defendida por intelectuais ${ }^{7}$ - como Demerval Saviani e os membros do Grupo de Trabalho então denominado Educação e Trabalho, ligado à Associação Nacional de Pós-Graduação e Pesquisa em Educação - pertencente aos grupos da sociedade civil dos anos 1980.

O embate à época realizava-se entre a politecnia e a polivalência, esta última defendida pelos empresários e seus intelectuais como a capacidade para o desempenho de várias tarefas, apoiada na mudança da produção industrial de caráter rígido pela de caráter flexível, contraposta à formação integral, defendida pela concepção politécnica. Documentos representativos da Confederação Nacional da Indústria (CNI, 1993) e discutidos por Oliveira (2003) refletem esta posição, protagonizada pelas políticas neoliberais.

No âmbito do Estado ampliado (GRAMSCI, 1987), a sociedade política (governo) do Paraná, incorpora na Política de Educação Profissional integrada elementos de uma formação politécnica e da escola unitária, diversamente da concepção hegemônica. Esta última, baseada nas competências, surge na Lei de Diretrizes e Bases da Educação Nacional (1996), nos Parâmetros Curriculares Nacionais (1999) e nas Diretrizes Curriculares Nacionais para o Ensino Médio e para a Educação Profissional (1999). Segundo Chauí (1997, p. 147), "[...] a desigualdade entre os detentores do saber e os despossuídos" reflete a dimensão política da "competência".

O avanço da concepção defendida, representando uma formação de caráter emancipatório para os alunos trabalhadores na Educação Profissional, necessita articular-se às ações presentes na implementação da política estadual paranaense.

7 Neste período, destacou-se pela sua ação institucional e docente nos cursos de Pós-Graduação de São Paulo (PUC/SP; UNICAMP e UFSCAR) o Professor Dermeval Saviani que desenvolveu a partir dos estudos de Marx e Gramsci, análises em diversas áreas da educação. Com referencial teórico-metodológico marxista, este intelectual crítico desenvolveu a Pedagogia Histórico-Crítica (nomenclatura adotada a partir de 1984) visando superar os limites das pedagogias não-críticas e das pedagogias crítico-reprodutivistas. Contribuiu para a formação de pesquisadores críticos no campo acadêmico, através de pesquisas referentes à defesa da escola pública e às iniciativas no âmbito educacional voltadas para os interesses da população. Em Desafios teórico-metodológicos da relação trabalho-educação e o papel social da escola, Kuenzer (1998) reflete que 0 GT então denominado Educação e Trabalho, constituído na década de 1980 e ligado à ANPED procurou através de trabalhos desenvolvidos por seus membros, compreender a pedagogia capitalista para a construção de uma nova pedagogia comprometida com os interesses dos trabalhadores, através dos espaços de contradição. Frigotto e Ciavatta (2006) em A formação do cidadão produtivo: a cultura de mercado no ensino médio técnico, mencionam os autores que publicam trabalhos na década de 1980. 


\section{A Política de Educação Profissional do Paraná: ações}

Mantendo a tendência nacional oposicionista no resultado da eleição estadual de 2002, iniciou-se o Governo de Roberto Requião ${ }^{8}$ (PMDB), em 2003, no Paraná. Representou uma mudança no grupo político do governo paranaense e, ao reeleger-se em 2006, realiza o seu terceiro mandato no Paraná.

Um importante compromisso de campanha consistia na retomada da Educação Profissional pública, uma demanda dos jovens paranaenses. Inserida nas propostas que dão início à construção do Plano Estadual de Educação (PARANÁ, 2004) procurou romper com a visão social de mundo dos anos 1990, expressa na Política de Educação Profissional estadual do período anterior, principalmente em relação à cessação da oferta pública e na defesa do acesso ao conhecimento como um direito social.

Uma política educacional que, no âmbito dos pressupostos, articula-se "[...] à ideia de direito social e de atendimento das necessidades de todos" e que, no âmbito do acesso procura realizar a "[...] igualdade de condições de oferta para o conjunto da população" representa, segundo Gouveia (2009, p. 43) uma Política Educacional no eixo de esquerda, de perspectiva democrática.

Uma das primeiras ações foi à criação do Departamento de Educação Profissional, atualmente denominado de Departamento de Educação e Trabalho (DET) no âmbito da SEED, extinguindo as atividades da Agência para o Desenvolvimento do Ensino Técnico do Paraná (PARANATEC), uma empresa civil que gerenciava a Educação Profissional.

Conforme o documento "Fundamentos Políticos e Pedagógicos para a Educação Profissional" (PARANÁ, 2005), a concepção de organização curricular integrada - tendo como eixos o trabalho, a cultura, a ciência e tecnologia - era objeto de debate, resultante do acompanhamento do processo de discussão que originou a revogação de Decreto n 2208/97 e que vinha sendo assumido pelo então Departamento de Educação Profissional, sob a chefia de Sandra Garcia, na gestão do Secretário de Educação Maurício Requião (2003-2008).

Esta concepção foi publicizada em encontros e seminários que desenvolveram a temática dos fundamentos e da proposta curricular para a Educação Profissional integrada no Paraná, especialmente em 2003 e 2004 , contando com a presença de pesquisadores como Gaudêncio Frigotto, Acácia Kuenzer, Marise Ramos, Maria Ciavatta, Domingos Leite Filho entre outros.

Os pesquisadores envolvidos na constituição da política de Educação Profissional integrada, tanto em relação à formulação, representada pela elaboração de sua concepção (o documento analisado anteriormente teve a assessoria de Acácia Kuenzer), como a sua publicização - que envolveu a discussão com os docentes da escola pública -, revela a categoria social de intelectuais críticos que defendem uma visão social de mundo, representativa do ponto de vista dos trabalhadores.

Com base em Gramsci (1991), pode-se pensar na participação política dos intelectuais que, defendendo uma concepção que representa uma visão social de mundo, consequentemente repercutiu na organização e implantação da Educação Profissional integrada no Paraná. Possuidores de um "capital cultural", estes intelectuais representam determinados grupos que lutam pela hegemonia no campo da Educação Profissional, a partir da discussão, desvendamento e crítica à sociedade capitalista.

Em 2003, o Conselho Estadual de Educação aprovou pelo Parecer n $1095 / 03$ as propostas curriculares e pelo Parecer $n^{\circ}$ 1028/03, o plano de expansão dos cursos - medidas legais para a expansão - anteriores à revogação do Decreto n²208/97. Assim, o Paraná tornou-se o estado pioneiro na retomada da Educação Profissional integrada ao Ensino Médio, implantando seus cursos a partir de 2004, anteriormente à vigência do Decreto $n^{\circ}$ 5154/04 e seguido pelo estado do Espírito Santo (FERREIRA; GARCIA, 2005).

80 seu discurso de posse em 11/01/2007 demarca no campo ideológico a sua posição política como defensor de interesses nacionais e populares; do papel do Estado como elemento essencial para a retomada do desenvolvimento; da reorganização do setor produtivo estatal, voltado aos interesses da maioria da população; da oposição às tendências de privatização e da auto-definiç̧ão como governo de esquerda. 0 discurso encontra-se disponível em: <http://www. aen.pr.gov.br/modules/noticias/article.php?storyid=25322>. Acesso em 22 jun. 2010. Sua análise encontra-se na dissertação de Saldanha (2010). 
Segundo a SEED (PARANÁ, 2009) a expansão que materializa a retomada da Educação Profissional caracterizouse pela oferta, até 2008, de 365 cursos na modalidade subsequente e 309 de ensino médio integrado - no início de 2003 restavam apenas 191 cursos profissionais. A SEED também assumiu a modalidade subsequente, com formação profissional na forma de pós-médio, que se encontrava em curso, àqueles que não puderam realizá-la, por força do desmonte ocorrido no período de 1997 a 2002 na Educação Profissional pública paranaense.

O documento objeto de análise (PARANÁ, 2005) menciona que se iniciou no DET "[...] a realização de diagnóstico para levantamento das reais necessidades de expansão, considerando tendências sócioeconômicas das regiões do Estado, como o provimento de recursos materiais e humanos" (PARANÁ, 2005, p. 8).

Na entrevista realizada com Sandra Garcia, chefe do DET, em julho de 2010 (SALDANHA, 2010, p. 75) menciona que no primeiro momento da expansão, houve o fortalecimento das escolas agrícolas e dos cursos na área de serviços. Através da análise geral dos cursos presentes no estado, confirma-se o número elevado de cursos técnicos de Administração e de Informática nas escolas. O aumento do setor de serviços atende ao cenário econômico de "desindustrialização" (ANTUNES; ALVES, 2004), de acordo com o padrão de acumulação flexível capitalista.

Através da Resolução no 03 de 09/07/2008 do Conselho Nacional de Educação (BRASIL, MEC/CNE/CEB, 2008), implanta-se o Catálogo Nacional de Cursos Técnicos, como um mecanismo de organização e orientação de oferta nacional dos cursos técnicos de nível médio. Conforme o Catálogo Nacional ${ }^{9}$, os cursos técnicos são, atualmente, divididos nos seguintes Eixos Tecnológicos: Formação de Docentes; Ambiente, Saúde e Segurança; Apoio Educacional; Controle e Processos Industriais; Gestão e Negócios; Hospitalidade e Lazer; Informação e Comunicação; Infra-Estrutura; Produção Alimentícia; Produção Cultural e Designer; Produção Industrial; Militar; Recursos Naturais.

Os cursos implantados no Paraná a partir da Resolução n 03/08 seguem os Eixos Tecnológicos e, os cursos implantados anteriormente, devem adaptar-se à Resolução. Na análise dos cursos por Eixo Tecnológico destacou-se o eixo de Ambiente, Saúde e Segurança, pelo maior número de cursos ligados à área da saúde nos Núcleos. A seguir, vem o Eixo Tecnológico Gestão e Negócios, relacionado aos cursos de Administração, Comércio, Comércio Exterior, Contabilidade, Logística, Recursos Humanos, Secretariado, Serviços de Condomínio, Transações Imobiliárias e Vendas pertencentes ao setor de serviços (assim como os do Eixo Tecnológico Ambiente, Saúde e Segurança), setor predominante na economia do estado do Paraná.

Em 2004 e 2007, no processo de reestruturação curricular - que apresentou uma orientação disciplinar, baseada em conteúdos - e, posteriormente, na reformulação, foram realizados encontros e reuniões com professores, diretores, coordenadores e equipe pedagógica dos Núcleos Regionais de Educação objetivando uma construção curricular coletiva, consideradas as dificuldades que este processo apresentou. De acordo com Gouveia (2009), no âmbito da gestão, o processo democrático e participativo representa outra característica de esquerda.

No contexto de formulação/implantação da política de Educação Profissional integrada fizeram parte das ações da SEED, a formação continuada do quadro docente através de simpósios, cursos de atualização e seminários. Em 2006 instituíram-se para a formação continuada, as modalidades de grupos de estudos nas escolas e oficinas regionais. Os primeiros encontros relativos à profissionalização na Educação de Jovens e Adultos foram realizados em 2007. Os concursos realizados em 2004 e 2007 dão início a uma política de recursos humanos para a Educação Profissional que, ainda, não é suficiente em relação a uma distribuição equilibrada de profissionais nos municípios e regiões do Paraná. A contratação constante durante os anos de 2003-2010 de profissionais temporários, através de processo seletivo simplificado (PSS), não garante um vínculo orgânico entre a Educação Profissional e estes professores/profissionais, configurando-se em mais um limite à implantação da Política de Educação Profissional no estado.

O programa "Brasil Profissionalizado", lançado em 2008 pelo governo federal, com a participação dos governos estaduais, objetivou a transferência de recursos federais aos estados para a construção de laboratórios próprios

9 Site: <http://catalogonct.mec.gov.br> 
e aquisição de equipamentos em escolas com o Ensino Médio integrado e PROEJA. Estes recursos provêm do orçamento da União e não de financiamentos internacionais, como ocorreu com o Programa de Expansão, Melhoria e Inovação do Ensino Médio (PROEM) ${ }^{10}$, implantado em 1996 no Paraná, através de recursos do Banco Interamericano de Desenvolvimento (BID). No entanto, o "Brasil Profissionalizado" constitui-se como um programa que não contempla a manutenção dos cursos, não se constituindo em política de financiamento. Os recursos para a Educação Profissional integrada (e não para as outras formas) encontram-se no FUNDEB, pois o estado não possui um recurso estadual definido para a Educação Profissional. Portanto, contraditoriamente à expansão realizada, os recursos não a acompanham e, consequentemente, a Educação Profissional integrada como política pública não se efetiva.

Em recente pesquisa sobre a Política de Educação Profissional integrada no Paraná, no âmbito da gestão, Garcia (2009) sintetiza que a "vontade política" representa um determinante importante, mas não único, apontando para a necessidade de uma política pública de financiamento que representa a categoria central para que as condições materiais se realizem e de acordo com os estudos de Grabowski e Ribeiro (2006).

O Paraná instituiu em 2006, um recurso descentralizado para cada colégio denominado Fundo Rotativo da Educação Profissional, destinado à manutenção dos laboratórios. Esta medida não resolve totalmente a questão, embora represente uma contribuição inicial ao processo (GARCIA, 2009).

\section{Considerações Finais}

Na análise do processo de constituição (concepção e ações) da atual Política de Educação Profissional integrada no Paraná (2003-2010), norteada pelo referencial teórico e consideradas as determinações estruturais e conjunturais inerentes em uma perspectiva histórico-política, o avanço conquistado pela retomada da sua oferta pública - que revela um processo de democratização do acesso ao conhecimento - e a sua concepção de formação humana, possibilitaram um movimento de transformação na superestrutura.

Limites e contradições fizeram parte do processo e de sua crítica, e não desmerecem a importância éticopolítica pela mediação da Política de Educação Profissional integrada na construção da travessia rumo à escola unitária. A postura e ações da classe detentora do capital no país têm impedido o rompimento das estruturas que produzem a desigualdade econômica, social, cultural e educacional; daí as reformas, a constante "modernização do arcaico" brasileira.

A desconsideração dos direitos elementares da maioria da população, da produção e da reprodução da miséria, convive com a presença da alta tecnologia que proporciona ganhos e concentração de capital e renda através de mão de obra barata. O projeto dominante insere-nos subalternadamente na divisão do trabalho simples, em relação ao núcleo orgânico das economias capitalistas, justificando o escasso investimento em educação, ciência e tecnologia.

O atual regime de acumulação flexível, submetido à racionalidade do capital e à lógica dos mercados no contexto das novas tecnologias, incorpora capital morto (ciência e tecnologia) no processo produtivo como forças produtivas do capital. Ao flexibilizar processos, mercados de trabalho, produtos e padrões de consumo e com a mudança da base de produção da mecânica para a microeletrônica, a acumulação flexível exige um trabalhador de maior qualificação, o que demanda o domínio de conhecimentos científico-tecnológicos e sócio-históricos, privilegiando uma formação com base na polivalência do trabalhador, atualmente denominada "laboralidade".

10 Segundo a análise de Deitos (2000) em Ensino médio e profissional e seus vínculos com o BID/BIRD: os motivos financeiros e as razões ideológicas da política educacional, caracterizam o PROEM a dimensão ideológica que reforça o mito da educação como promotora do desenvolvimento e meio para ascensão social e os interesses financeiros. O Programa apresentou cursos profissionais na modalidade pós-médio em onze complexos profissionalizantes centralizados nas principais cidades do estado. 0 currículo desenvolveu-se priorizando as habilidades, envolvendo a afetividade e 0 compromisso com as empresas para um trabalhador mais produtivo. A escola tornou-se, operacional e não-emancipadora. 
O papel da escola ao possibilitar o domínio dos conhecimentos científico-tecnológicos e sócio-históricos que o mundo do trabalho exige, permite - por contradição -, a compreensão crítica da realidade, se os conhecimentos forem apropriados pelos trabalhadores na perspectiva de autonomia intelectual e ética, buscando a emancipação das relações de trabalho alienadas.

A Reforma do Estado provocou a separação da Educação Profissional do Ensino Médio, consolidando a histórica dualidade, e a escola paranaense sofreu os efeitos da diminuição ou exclusão da oferta pública de Educação Profissional no final do século XX.

A partir de 2003, intelectuais vinculados às lutas e movimentos sociais integram as esferas da sociedade política, compondo o governo do Paraná, articulados à posição político-ideológica de Roberto Requião, que se opôs à política de cessação da Educação Profissional do governo liberal anterior. Incorporou-se, na sociedade política do Paraná, a concepção desenvolvida por intelectuais progressistas pertencentes à sociedade civil.

A Política de Educação Profissional integrada do Paraná (2003-2010) apresenta uma proposta de concepção na perspectiva de formação humana, baseada nos princípios da politecnia e da escola unitária, presentes nos debates educacionais da história recente da educação brasileira, no final dos anos 1980 e dos anos 1990. A sociedade política articulou-se aos grupos da sociedade civil para a formação de uma ideologia, uma "visão social de mundo" que, presente na Educação Profissional integrada ao Ensino Médio no Paraná, faz parte de um projeto político de sociedade e educação.

A Educação Profissional integrada pretende atender aos milhões de jovens paranaenses que trabalham para garantir o seu sustento, possibilitando-Ihes uma formação que Ihes permita fazer parte do mundo do trabalho e compreender a contradição entre trabalho e capital, presente na sociedade de classes capitalista. Através da autonomia conquistada pela formação humana é possível lutar pela sua superação.

Os conceitos de ideologia e de Estado ampliado são acrescidos pelo conceito de intelectuais de Gramsci (1991), como organizadores da cultura. Destacou-se também, na constituição da Política, o papel de intelectuais críticos ligados às esferas do governo (Sandra Garcia) e das Universidades Públicas como Gaudêncio Frigotto, Acácia Kuenzer, Domingos Leite Filho entre outros. Ao defenderem a concepção de formação na perspectiva da integralidade - publicizada em vários encontros de formação com os professores -, imprimiram uma direção ético-política à Política de Educação Profissional integrada no Paraná.

Esta Política apresenta os eixos norteadores do trabalho, da ciência, da tecnologia e da cultura que servem de base para o desenvolvimento dos conhecimentos. Ressalta-se o sentido ontológico do trabalho que produz o ser humano, em oposição ao sentido histórico do trabalho ligado às relações capitalistas de produção que dividem o ser, provocando a alienação. Os fundamentos científicos que embasam as modernas técnicas e tecnologias de produção, articulados aos contextos sócio-culturais de suas produções têm a possibilidade de serem apreendidos na integração Educação Profissional e Ensino Médio, mediante uma formação profissional necessidade que advém da própria realidade - mais completa.

A principal contradição referiu-se à falta de uma política pública de financiamento que ampliasse os recursos às escolas, na proporção da expansão realizada, comprometendo a materialidade da proposta. Embora haja um aumento de investimento em profissionais para a Educação Profissional, estes também se revelaram insuficientes.

O processo de constituição da Educação Profissional integrada no Paraná (2003-2010) representa a síntese de fatores sociais, políticos e econômicos e faz parte de um projeto educacional e de sociedade que procura garantir de forma pública, o acesso ao conhecimento e à formação integral - pressupostos do currículo integrado - através da reflexão crítica ao conjunto das relações sociais do capitalismo, na tentativa de construção da autonomia dos sujeitos, condição para a emancipação dos jovens trabalhadores e travessia para a escola unitária.

O debate dos anos 1980 continua presente e atual. Necessita ser retomado e fortalecido através de futuras pesquisas que tenham como horizonte a defesa da escola pública, universal, gratuita, laica, de qualidade e unitária. 


\section{Referências Bibliográficas}

ANTUNES, R.; ALVES, G. As mutações no mundo do trabalho na era da mundialização do capital. Educação

\& Sociedade, Campinas, v. 25, n. 87, p. 335-351, maio/ago. 2004.

ARROYO, M. G. Indagações sobre currículo: educandos e educadores: seus direitos e o currículo. Organização do documento: Jeanete Beauchamp, Sandra Denise Pachel, Aricélia Ribeiro do Nascimento. Brasília: Ministério da Educação, Secretaria da Educação Básica, 2007.

BOBBIO, N. Direita e esquerda: razões e significados de uma distinção política. Tradução de Marco Aurélio Nogueira. 3. reimp. São Paulo: Ed. UNESP, 1995.

BRASIL. Lei nº 9394 de 20 de dezembro de 1996. Lei de Diretrizes e Bases da Educação Nacional. Brasília, 1996. MEC/SETEC. Educação Profissional Técnica de Nível Médio Integrada ao Ensino Médio. Documento Base. Brasília: MEC/SETEC, 2007.

. Lei $\mathbf{n}^{\circ} \mathbf{1 1 . 7 4 1}$ de $\mathbf{1 6}$ de julho de 2008. Altera dispositivos da Lei no 9394, de 20 de dezembro de 1996, que estabelece as diretrizes e bases da educação nacional, para redimensionar, institucionalizar e integrar as ações da educação profissional técnica de nível médio, da educação de jovens e adultos e da educação profissional e tecnológica. Brasília, 2008. Disponível em: <http://www.leidireto.com.br/lei-11741.html>. Acesso em: 06 jul. 2010.

MEC/CNE/CEB. Resolução n 3, de 9 de julho de 2008. Dispõe sobre a instituição e implementação do Catálogo Nacional de Cursos Técnicos de Nível Médio. Diário Oficial da União, Brasília, 10 de julho de 2008, seção 1, p. 9.

MEC/SETEC/SEB. Ensino Médio Integrado: uma perspectiva abrangente na política pública educacional. Brasília: MEC/SETEC/SEB, 2008.

MEC/CNE. Versão Preliminar para debates na Audiência Pública Nacional. Trata da Atualização das Diretrizes Curriculares Nacionais para a Educação Profissional Técnica de Nível Médio. Relator Francisco Aparecido Cordão. Brasília: CEB, 2010.

CARDOSO, M. L. Sobre a teorização do capitalismo dependente em Florestan Fernandes. In: FÁVERO, O. Democracia e educação em Florestan Fernandes. Campinas: Autores Associados; Niterói: EDUFF, 2005.

CHAUÍ, M. de S. Cultura e democracia: o discurso competente e outras falas. São Paulo: Cortez, 1997.

CIAVATTA, M. A Formação Integrada: a escola e o trabalho como lugares de memória e de identidade. In: FRIGOTTO, G; CIAVATTA, M.; RAMOS, M. (Orgs.). Ensino Médio Integrado: concepção e contradições. Cortez: São Paulo, 2005. p.83-105.

DEITOS, R. A. Ensino médio e profissional e seus vínculos com o BID/BIRD: os motivos financeiros e as razões ideológicas da política educacional. Cascavel, PR: Edunioeste, 2000.

FERNANDES, F. Capitalismo dependente e classes sociais na América Latina. Rio de Janeiro: Zahar, 1975. Nova República? Rio de Janeiro: Zahar, 1985.

FERREIRA, E. B.; GARCIA, S. R. de O. O ensino médio integrado à educação profissional: um projeto em construção nos estados do Espírito Santo e do Paraná. In: Ensino Médio Integrado: concepção e contradições. Cortez: São Paulo, 2005. p.148-173

FRIGOTTO, G. Fundamentos científicos e técnicos da relação trabalho e educação no Brasil de hoje. In: LIMA, J. F.; NEVES, L. M. W. Fundamentos da educação escolar no Brasil contemporâneo. Rio de Janeiro, 2006. p. 241-288.

Palestra de Abertura no I Seminário de Pesquisa em Educação do Campo, Educação do Campo: desafios teóricos e práticos. UFSC: 04 a 06 de novembro de 2009.

FRIGOTTO, G.; CIAVATTA, M. (Orgs.). A formação do cidadão produtivo: a cultura de mercado no ensino médio técnico. Brasília: INEP, 2006. 
FRIGOTTO, G.; CIAVATTA, M.; RAMOS, M. (Orgs.) Ensino Médio Integrado: concepção e contradições. Cortez: São Paulo, 2005.

GARCIA, S. R. de O. A educação profissional integrada ao Ensino Médio no Paraná: avanços e desafios. 2009. 147 f. Tese (Doutorado em Educação) - Universidade Federal do Paraná, Curitiba, 2009.

GOTARDO, R. C. da C.; VIRIATO, E. O. Integração curricular: o ensino médio integrado e o proeja. Revista Theomai, n. 20, p. 222-233, 2009, Disponível em: <http:www.revista-theomaiunq.edu.ar/Numero20/13ArtGotardo. pdf $>$. Acesso em: 30 set. 2010.

GOUVEIA, A. B. Direita e esquerda na política educacional: democracia, partidos e disputas entre projetos de administração pública municipal no Brasil. Revista Brasileira de Estudos Pedagógicos, Brasília, v. 90, n. 224, p. 32-58, jan./abr. 2009.

GRABOWSKI, G; RIBEIRO, J. A. R. Financiamento da Educação Profissional no Brasil: Contradições e Desafios. Porto Alegre: 2006.

GRAMSCI, A. Cartas do cárcere. 3. ed. Tradução de Noênio Spínola. Rio de Janeiro: Civilização Brasileira, 1987. Os intelectuais e a organização da cultura. Tradução de Carlos Nelson Coutinho. 8. ed. Rio de Janeiro: Civilização Brasileira, 1991.

GUIMARÃES, E. R. Política para o ensino médio e educação profissional. SEED/PR, 2007. (Texto reproduzido pela SEED para a Semana Pedagógica).

HARVEY, D. A condição pós-moderna. 6. ed. São Paulo: Edições Loyola, 1992.

KUENZER, A. Desafios teórico-metodológicos da relação trabalho-educação e o papel social da escola. In: FRIGOTTO, G. (Org.). Educação e crise do trabalho: perspectivas do final de século. Petrópolis: Vozes, 1998. p.55-75.

LÖWY, M. As aventuras de Karl Marx contra o Barão de Münchausen: marxismo e positivismo na sociologia do conhecimento. 9. ed. São Paulo: Cortez, 2007.

NOSELLA, P. Trabalho e perspectivas de formação dos trabalhadores: para além da formação politécnica. Revista Brasileira de Educação, Rio de Janeira, v. 12, n. 34, p. 137-151, jan./abr. 2007.

OLIVEIRA, F. de. A economia brasileira: crítica à razão dualista. Petrópolis: Vozes; CEBRAP, 1972.

OLIVEIRA, R. Empresariado industrial e educação profissional brasileira. Educação e Pesquisa, São Paulo, v. 29, n. 2, p. 249-263, jul./dez. 2003.

PARANÁ. Secretaria de Educação do Estado do Paraná. Estudos Temáticos para o Plano Estadual de Educação. Resultados do I Seminário Integrador. Jul. 2004.

. Secretaria de Educação do Estado do Paraná. Departamento de Educação Profissional. Educação profissional na rede pública estadual: fundamentos políticos e pedagógicos. Curitiba: SEED, 2005.

Secretaria de Estado da Educação. Departamento de Educação e Trabalho. Ações Educacionais da SEED. Educação Profissional, 2009.

SALDANHA, L. de L. W. Avanços e Contradições da Política de Educação Profissional Integrada no Paraná (2003-2010). 2010. 140 f. Dissertação (Mestrado em Educação) - Universidade Estadual de Ponta Grossa, Ponta Grossa, 2010.

SAVIANI, D. Sobre a concepção de politecnia. Rio de Janeiro: FIOCRUZ, Politécnico de Saúde Joaquim Venâncio, 1989.

VÁZQUEZ, A. S. F. Filosofia da práxis. Rio de Janeiro: Paz e Terra, 1968.

ZIBAS, D. M. L. Refundar o Ensino Médio? Alguns antecedentes e atuais desdobramentos das políticas dos anos de 1990. Educação \& Sociedade, Campinas, v. 26, n. 92, p. 1067-1086, out. 2005. 